\title{
SOCIOECONOMIC DIFFERENCES IN THE IMPACT OF SMOKING TOBACCO AND ALCOHOL PRICES ON SMOKING IN INDIA
}

\author{
G. Emmanuel Guindon \\ Arindam Nandi \\ Frank J. Chaloupka, IV \\ Prabhat Jha \\ Working Paper 17580 \\ http://www.nber.org/papers/w17580 \\ NATIONAL BUREAU OF ECONOMIC RESEARCH \\ 1050 Massachusetts Avenue \\ Cambridge, MA 02138 \\ November 2011
}

We thank the Bill \& Melinda Gates Foundation for providing financial support for this research. We thank Cuiping Long for her excellent research assistance, Jitender Sudhir, Prabha Sati, and Renu Joseph for support in obtaining data, PC Mohanan and the National Survey Organization (NSSO), New Delhi for guidance in using NSS data and Rijo John for helpful discussions. We are indebted to Angus Deaton for providing public access to his Stata codes. The views expressed herein are those of the authors and do not necessarily reflect the views of the National Bureau of Economic Research.

NBER working papers are circulated for discussion and comment purposes. They have not been peerreviewed or been subject to the review by the NBER Board of Directors that accompanies official NBER publications.

(C) 2011 by G. Emmanuel Guindon, Arindam Nandi, Frank J. Chaloupka, IV, and Prabhat Jha. All rights reserved. Short sections of text, not to exceed two paragraphs, may be quoted without explicit permission provided that full credit, including (C) notice, is given to the source. 
Socioeconomic Differences in the Impact of Smoking Tobacco and Alcohol Prices on Smoking in India

G. Emmanuel Guindon, Arindam Nandi, Frank J. Chaloupka, IV, and Prabhat Jha

NBER Working Paper No. 17580

November 2011

JEL No. H2,I18

\begin{abstract}
The threat posed by smoking to health in India is severe. Already 1 in 5 of all adult male deaths and 1 in 20 of all adult female deaths at ages 30-69 are due to smoking and India will soon have 1 million smoking deaths a year. Increasing tobacco prices has been found to be the single most effective method to reduce smoking. Yet, bidis, the most common form of smoked tobacco in India, are largely untaxed, while cigarettes are taxed at about $40 \%$ of retail price, well below the $65-80 \%$ rate noted by the World Bank in countries with effective tobacco control policies. Moreover, low and stagnant tax rates have occurred in a period in which all tobacco products have become more affordable with income growth. First, we use data from the most recent three consecutive quinquennial National Sample Survey (NSS) rounds (NSS 50, 55 and 61 conducted in 1993/94, 1999/00 and 200/05) and a two-equation system of budget shares and unit values that attempts to correct for quality and measurement error. Second, we pool data from the most recent nine rounds of NSS (NSS 55-57, 59-64, conducted between 1999/00 to 2007/08). Our analyses of single and repeated cross-sections yield own-price elasticity for bidis that are roughly in keeping with existing evidence. We find that a $10 \%$ increase in bidi prices would reduce the demand for bidis by about 6 to $9.5 \%$. We find, however, that own-price elasticity for cigarettes in India is substantially larger than previously thought. Our estimates suggest that cigarette users are at least as responsive as bidi users to price changes. On the whole, our analyses suggest that low SES households are likely more responsive to price changes than high SES households. Our analyses also uncovers important and policy-relevant cross-prices effects. Findings from this study provide additional evidence of the effectiveness of tobacco prices at reducing tobacco use.
\end{abstract}

\author{
G. Emmanuel Guindon \\ University of Waterloo \\ Propel Centre for Population Health Impact \\ Lyle S. Hallman Institute \\ 200 University Ave. West \\ Waterloo, ON, N2L 3G1, Canada \\ egguindon@uwaterloo.ca \\ Arindam Nandi \\ The Center for Disease Dynamics, \\ Economics \& Policy \\ 1616 P St NW, Ste 600 \\ Washington DC 20036 \\ nandi@cddep.org
}

Frank J. Chaloupka, IV

University of Illinois at Chicago

Department of Economics (m/c 144)

College of Liberal Arts and Sciences

601 S. Morgan Street, Room 713

Chicago, IL 60607-7121

and NBER

fjc@uic.edu

Prabhat Jha

University of Toronto

Centre for Global Health Research

LKSKI/KRC, St. Michael's Hospital

30 Bond Street, Toronto, ON, M5B 1W8, Canada jhap@smh.ca 


\section{INTRODUCTION}

Tobacco smoking and chewing are both common in India (Government of India, 2010; Rani et al., 2003), but the individual risks from smoking are markedly greater (Gajalakshmi et al., 2003; Jha et al., 2008). Already 1 in 5 of all adult male deaths and 1 in 20 of all adult female deaths at ages 30-69 are due to smoking and India will soon have 1 million smoking deaths a year (Jha et al., 2008). The direct medical costs of treating smoking tobacco attributable diseases in India have been estimated to exceed $\$ 900$ million in 2004 (John et al., 2009). Moreover, the use of tobacco has been associated with impoverishment through borrowing and distress selling of assets due to costs of hospitalization (Bonu et al., 2005). The most common type of smoking tobacco product are bidis, followed by cigarettes. ${ }^{1}$ While both increase the risks of death (even only a few bidis a day), smoking cigarettes, especially at daily amounts common in high-income Western countries appears to confer especially high risks (Jha et al., 2008). Smoking in India varies hugely by product and rural/urban strata and is more common among the poor and less educated (Government of India, 2010).

Increasing tobacco prices has been found to be the single most effective method to reduce smoking (Chaloupka and Warner, 2000; International Agency for Research on Cancer, 2011). Yet, bidis, the most common form of smoked tobacco in India, are largely untaxed, while cigarettes are taxed at about $40 \%$ of retail price, well below the $65-80 \%$ rate noted by the World Bank in countries with effective tobacco control policies (Jha and Chaloupka, 1999; Jha et al., 2011). Moreover, low and stagnant tax rates have occurred in a period in which all tobacco

\footnotetext{
${ }^{1}$ Also known as beedis, beeris or biris, bidis are slim, hand-rolled, unfiltered cigarettes rolled in a tendu leaf or temburni leaf and held together by a cotton thread that contain about $1 / 4$ the tobacco of cigarettes. Bidis are available branded and unbranded and are four to eight cm in length (John, 2008b).
} 
products have become more affordable with income growth (Jha et al., 2011). The lack of sustained increases in taxation is in part due to misconceptions about severe economic harm to the poor. Consumption taxes, such as those imposed on tobacco, are sometimes described as regressive. A tax is said to be regressive if the ratio of tax paid to income is lower for higherincome groups. If the poor are more responsive to changes in prices, an increase in tobacco taxes would lead to a relatively larger reduction in tobacco use among the lowest income group (relative to higher-income groups) and generally encourage that group to reduce smoking and thus mitigate the large economic burden that it imposes, making an increase in tobacco tax even progressive.

There is a small but growing body of research that examines the effect of tobacco prices on tobacco use in India specifically and more generally in countries of South Asia. John (John, 2005; John, 2008a) using data from two quinquennial rounds of the National Sample Survey (NSS) of India conducted in 1993/94 and 1999/00 (NSS 50 and NSS 55) finds negative and significant own-price elasticities for bidis with effect sizes ranging between -0.7 and -0.9 with no substantial differences between rural and urban households. John using NSS 50 finds positive and insignificant own-price elasticity for cigarettes while using NSS 55, he finds negative ownprice elasticity of cigarettes but only significant for rural household with effect sizes of about 0.35. Finally, John, using NSS 55 also finds weak evidence that cigarettes and bidis may be complements among rural households.

Research conducted using data from Bangladesh (Nargis et al., 2010), Nepal (Karki et al., 2003), Pakistan (Mushtaq et al., 2011), Sri Lanka (Arunatilake, 2002) and time-series cross-sectional 
data from seven South-East Asia countries (Guindon et al., 2003) suggest that individuals of South Asia are responsive to changes in the prices of cigarettes and bidis. Effect sizes, however, vary substantially within and across studies. Nargis et al. (2010) using data from the 2009 International Tobacco Control Bangladesh Survey and two-part models find negative and statistically significant own-price participation elasticities for bidis (-0.46) and cigarettes $(-0.29)$ but fairly small own-price conditional elasticities. Own-price participation elasticities for bidis and cigarettes are found to be substantially higher among low- and mid-socioeconomic status (SES) individuals relative to high-SES individuals. Karki et al. (2003) using data from the 2000 Nepal Smoking Behaviour Survey and two-part models find fairly large own-price participation (-0.46) and conditional (-0.42) elasticities for bidis/cigarettes. Own-price conditional elasticities, but not participation, are found to be higher among low- and mid-SES individuals relative to high-SES individuals. Arunatilake (2002) using household-level data from the 1999/2000 Sri Lanka Integrated Survey and two-part models finds that tobacco prices have no effect on tobacco use participation but fairly large and statistically significant effect on tobacco consumption. Own-price conditional elasticities are not found to vary between SES categories. Mushtaq et al. (2011) using aggregate annual data (1981-2009) and autoregressive distributed lag models find fairly large and statistically significant short-run (-0.48) and long-run (-1.17) total own-price elasticities for cigarettes. Guindon et al. (2003) use time-series cross-sectional data from seven South-East Asia countries (Bangladesh, Burma, Indonesia, Maldives, Nepal, Sri Lanka, and Thailand) and various estimators (OLS, GLS, 2SLS, Andersen-Hsiao) and find moderate to large statistically significant short-run total own-price elasticities (-0.10 to -0.65) and large and statistically significant long-run total own-price elasticities (-0.80 to -1.40$)$. 
The scarcity of India-specific research combined with the heterogeneity in methods and findings of other South Asian studies warrants additional research. Moreover, little research has explored the complementarity or substitutability between different tobacco products such as bidis and cigarettes and between tobacco and alcohol products in countries of South Asia and more generally in low- and middle-income countries. More importantly, the sheer current and projected death and health toll attributable to smoking in India warrants, in and of itself, additional research that can inform decision makers interested in improving the health and quality of life of the Indian population.

\section{DATA AND METHODS}

First, we use data from the most recent three quinquennial NSS rounds and a two-equation system of budget shares and unit values proposed by Deaton (Deaton, 1990, 1997) that attempts to correct for quality ${ }^{2}$ and measurement error. Second, we pool data from the most recent nine rounds of NSS (NSS 55 to NSS 64) ${ }^{3}$ and use a simple share-log functional form (Deaton, 1989; Gibson and Rozelle, 2005).

The National Sample Survey Organization (NSSO) conducts nationally representative socioeconomic surveys of households covering various subjects on a near-annual basis. The primary focus of the five-yearly rounds generally are the characteristics of the household, including detailed information on consumption expenditure and demographic and employment characteristics of individual members. The survey duration typically spans a year and

\footnotetext{
${ }^{2}$ Deaton defines quality as "the value of a bundle of goods at fixed reference prices relative to its physical volume (Deaton, 1997 p. 297)".

${ }^{3}$ NSS 50 does not have district identifiers; NSS 58's data dictionary contains errors that prevent us from appropriately reading the data files; and, NSS 65 does not have household consumer expenditure component.
} 
approximately two-thirds of the surveyed households are from rural areas. NSS quinquennial rounds are generally conducted in all states and union territories between July and June. NSS 50 was conducted from July 1993 to June 1994. A total of 115,354 households (69,206 rural and 46,148 urban) were surveyed from 6951 villages and 4650 urban blocks. NSS 55 survey was conducted between July 1999 and June 2000. Data were collected from 71,385 rural households from 5997 villages and 48,924 urban households from 4107 urban blocks. NSS 61 conducted between July 2004 and June 2005, covered a sample of 79,298 rural and 45,346 urban households spread over 7999 villages and 4602 urban blocks, respectively. Table A1 summarizes the timing, number of households, urban/rural distribution, village/urban block distribution for all NSS rounds used in the analyses.

We use information from the household consumption expenditure questionnaire (Schedule 1.0) of each of NSS surveys described above. Schedule 1.0 collects detailed data on the consumption of various durable and nondurable goods, and services. For each commodity, total quantity consumed and the total value of consumption by the household are recorded. For food and intoxicant items, all NSS rounds used a recall period of 30 days while NSS 55 round used two distinct recall periods (30 days and 7 days). We used consumption data collected under a 30 day recall period for all survey rounds. ${ }^{4}$ Among the tobacco products and other intoxicants included in Schedule 1.0, we focus on the most popular smoking products: bidis and cigarettes. We also explore the cross-price effects between smoking tobacco products and the most popular alcohol

\footnotetext{
${ }^{4}$ John (2005) used both 30-day and 7-day recall data in his analyses and found qualitatively similar results. NSS 60 used a 30-day and 7-day recall on distinct households (unlike NSS 55 that used both recall periods on the same households). We only include in our pooled analyses households that reported their expenditures and consumption using a 30-day recall period.
} 
product, country liquor. ${ }^{5}$ We do not examine 'leaf tobacco' even though it is consumed by a nonnegligible number of household (about 12-15\%). First, various types of leaf tobacco are included in the product category 'leaf tobacco', including chewable tobacco and leaf tobacco burnt and powdered for brushing teeth. Second, our examination of unit values finds that leaf tobacco unit values sometimes have bi-modal distributions. A small number of households (substantially less than 1\%) report consuming home-grown or having received as gifts bidis, cigarettes or country liquor; we exclude them from our analyses. ${ }^{6}$

We inspected unit values for outliers. First, we charted box plots and histograms. Second, we removed unit values whose logarithms lied more than 5 standard deviations from the mean (Cox and Wohlgenant, 1986; Deaton and Tarozzi, 2000; Gibson and Rozelle, 2005; Prais and Houthakker, 1955). To ensure models are not sensitive to alternative approaches, we performed sensitivity analyses: first, we included all unit values - even the ones that are absurdly high and low - to allow comparison with earlier research; ${ }^{7}$ second, we removed unit values whose logarithms lied more than 2.5 standard deviations from the mean of logarithms.

Unit values, unlike market prices, are affected by the choice of quality: at least to some extent, a unit value is chosen. For example, wealthier households may tend to purchase higher priced cigarettes so that reported unit values may be positively related to total expenditure. Because unit values are derived from reported expenditures and quantities, measurement error in both quantity

\footnotetext{
${ }^{5}$ Country liquor is a locally distilled products made from fruits and grain such as sugar cane, palm, coconut and rice (Chowdhury et al., 2006; Gupta et al., 2003).

${ }^{6}$ The datasets obtained from NSSO for NSS 50, 56 and 57 do not contain a 'source code'. Hence, we are unable to exclude smoking tobacco or country liquor that are homegrown or that have been received as gifts.

${ }^{7}$ For example, John (John, 2005; John, 2008a) do not remove any outliers: bidi unit values of 0.004 Rs and 100 Rs per stick and cigarette unit values of 0.025 Rs and 200 Rs per stick are included.
} 
and expenditure will be transmitted to measurement error in the unit value. The two equations for the budget share and unit value are:

$$
\begin{aligned}
& w_{g h c}=\alpha_{g}^{0}+\beta_{g}^{0} \ln x_{h c}+\gamma_{g}^{0} z_{h c}+\sum_{H=1}^{N} \theta_{g h} p_{h c}+\left(f_{g c}+u_{g h c}^{0}\right) \\
& \ln u v_{g h c}=\alpha_{g}^{1}+\beta_{g}^{1} \ln x_{h c}+\gamma_{g}^{1} z_{h c}+\sum_{H=1}^{N} \psi_{g c} \ln p_{h c}+u_{g h c}^{1}
\end{aligned}
$$

where: $w_{g h c}$ is the share of the budget devoted to good $g$, by household $h$ in cluster $c, u v_{g h c}$ is the unit value of good $g$, by household $h$ in cluster $c, x$ is total expenditure, $p$ is the unobserved price of the good, $f$ is a cluster-level effect and $u_{g h c}^{0}$ and $u_{g h c}^{1}$ are idiosyncratic errors.

Deaton's two-equation system approach assumes there is no price variations within each cluster. The validity of this assumption requires both geographical proximity of the households and that households be interviewed at approximately the same time (Deaton, 1990). Hence, the variation in unit values within each cluster reflects differences in quality and measurement errors. The variation in budget shares and unit values within clusters is used to identify the effect of total household expenditures, household size and other household characteristics on the quantity and quality demanded. The coefficients $\beta_{g}^{0}$ and $\beta_{g}^{1}$ represent the elasticity of quantity demanded with respect to total expenditure and the elasticity of the unit value with respect to total expenditure (i.e. quality elasticity). The total expenditure elasticity is $\varepsilon_{x}=1-\beta_{g}^{1}+\beta_{g}^{0} / w_{g}$ where budget shares are evaluated at their means.

Implementing Deaton's approach involves three stages. First, the effects of household characteristics are removed from budget shares and unit values (i.e. purging the quality effects). Second, adjusted budget shares and unit values, averaged by cluster are used to estimate 
between-cluster error-in-variables regressions. In the third stage, the price and quality effects are disentangled relying on a separability assumption. We use the symmetry restrictions to add to the precision of the parameter estimates. ${ }^{8}$

Household surveys typically collect data on clusters of households that live together in the same rural or urban geographical areas (Deaton, 1989). In India, clusters are typically villages in rural areas and urban blocks ${ }^{9}$ in urban areas. As noted by Deaton, a potential problem is that cluster sizes are often quite small, sometimes as small as four or six households. Even after averaging at the village- and urban block-level, the measurement error may remain quite serious (Deaton, 1989). The measurement error will likely be more severe for goods that are consumed by few households. Such is the case of tobacco products such as bidis and especially cigarettes that are consumed by only a minority of households. An additional problem is that if none of the household surveyed in a particular cluster have positive consumption, every household in such a cluster ends up being removed from the unit value regressions. Table 1 presents descriptive statistics for cluster-level unit values. We present descriptive statistics for unit values at both village/urban block- and district-level. ${ }^{10}$ A district is an administrative region of a state or territory. As is traditionally done, we treat villages and urban blocks as clusters. Additionally, because most households do not consume any cigarettes, we treat districts as clusters. The latter approach assumes there is no price variations within each district. As mentioned earlier, the validity of this assumption requires both geographical proximity of the households and that

\footnotetext{
${ }^{8}$ The substitution matrix of the demand system is symmetric if, and only if, $\theta_{g h}+\beta_{g}^{0} \bar{w}_{h}=\theta_{h g}+\beta_{h}^{0} \bar{w}_{g}$.

${ }^{9}$ Each city or town are demarcated into urban blocks: small, compact subdivisions each having a population of about 600 to 800, or 120 to 160 households (Government of India, 2001).

${ }^{10}$ As of 1 January 2011, there were 631 districts, 28 states and 7 Union territories. In 1999, there were 543 districts, 25 states and 7 Union territories, while in 2004, there were 555 districts, 28 states and 7 Union territories.
} 
households be interviewed at approximately the same time. NSSO interviews households within the same villages or urban blocks at approximately the same time. The same, however, is not true for households within the same district who are sampled throughout the year. This is unlikely to be of consequence, however, as overall inflation was relatively modest in 1999/00 and 2004/04. We nevertheless perform sensitivity analyses and adjust unit values and total expenditures for overall inflation.

We apply Deaton's approach to the three most recent quinquennial rounds of NSS consumer expenditures surveys (NSS 50, 55 and 61). We present results treating both villages/urban blocks and districts as clusters for NSS 55 and 61. For NSS 50 we only present results treating villages/urban blocks as clusters because NSS 50 does not contain a district identifier.

The low mean number of households with non-zero purchases of cigarettes (i.e. about 2 per village or urban block) renders the examination of subsamples problematic. Additionally, an important feature of Deaton's approach is that its consistency properties depend on the number of clusters (and not on the number of households). Hence, in order to examine the impact of smoking tobacco and alcohol prices across socioeconomic strata, we pool the most recent nine NSS rounds (NSS 55-57, 59-64), treating districts as clusters, and use a share-log functional form (Deaton, 1989; Gibson and Rozelle, 2005):

$$
w_{g h}=\alpha_{g}+\beta_{g} \ln x_{h}+\gamma_{g} z_{h}+\sum_{H=1}^{N} \theta_{g j h} p_{j h}+u_{g h}
$$

where $w_{g h}$ is the share of the budget devoted to good $g$, by household $h, x$ is total household expenditure, $\mathrm{z}$ is a vector of household characteristics, $p_{j h}$ are prices (using unit values as 
proxies) and $u_{g h}$ are idiosyncratic errors. The price elasticities are $\varepsilon_{g j}=\theta_{g j} / w_{g}-\delta_{g j}$ where $\delta_{g j}$ is the Kronecker delta (equal to 1 if $g=j$ or to 0 otherwise) and budget shares are evaluated at their means. We adjust all unit values and total expenditures to constant July-September 2004 Rs (i.e. NSS sub-round/quarter 1) using India’s consumer price index for industrial workers (CPI-IW). We average unit values by cluster and include only households under examination. For example, when examining the price responsiveness of rural households, we average unit values by cluster using only unit values reported by rural households. As a sensitivity check, we estimate models where we average unit values by cluster over all households. In order to capture regional and temporal variations that may be related to price, we include quarterly and regional dummies. ${ }^{11}$ The boundaries of several districts and some states have changed between NSS 55 and NSS $64 .{ }^{12}$ We recode all districts and states to ensure that they represent the same geographic area between all NSS rounds.

As various household characteristics that determine a household’s taste and preferences may also affect a household's choice of unit value or budget share, in addition to total monthly household expenditures, household size, we included the following controls: religion (Hindu, Islam, Christian, Sikh, others), urban/rural strata, share of men in household, share of adults in household, and household head's education (seven binary indicators ranging from 'not literate'

\footnotetext{
${ }^{11}$ We include dummies for NSS regions $(\mathrm{n} \approx 75)$ in our village/urban block models and dummies for India regions $(\mathrm{n}=6)$ in our district models. India regions are coded as follows: Central (Chhattisgarh, Madhya Pradesh, Rajasthan, Uttar Pradesh); East (Bihar, Jharkhand, Orissa, West Bengal); North (Chandigar, Delhi, Himachal Pradesh, Haryana, Jammu \& Kashmir, Punjab, Uttaranchal); Northeast (Arunachal Pradesh, Assam, Meghalaya, Manipur, Mizoram, Nagaland, Sikkim, Tripura); South (Andaman \& Nicober, Andhra Pardesh, Karnataka, Lakshadweep, Kerala, Tamil Nadu, Pondicheri); West (Daman \& Diu, Dadra \& Nagar Haveli, Goa, Gujarat, Maharastra).

${ }^{12}$ For example, in 1995 Karur and Perambalur districts split from Tiruchirappalli District. In 2001, the Ariyalur district was carved out of Perambalur district, merged back with Perambalur in 2002 and split again in 2007. Our district and state coding schemes is available upon request.
} 
to 'above secondary education'), sex, age and age squared. In our pooled analyses, we included dummy indicators for NSS rounds. We estimated Deaton's two-equation system of budget shares and unit values using Stata codes made available by Deaton (Deaton, 1997). We estimated the share-log functional form specification using multilevel regressions. Three-level models were fit for household $h$ nested within district $d$ nested within state $s$. The hierarchical structure of our dataset was 477,007 households nested within 471 districts nested within 34 states. ${ }^{13}$ The average number of observations within each level was: 1012 households per districts, and 14 districts per state. All models were estimated using Stata/MP 11.2 for Macintosh.

\section{RESULTS}

Table 1 presents descriptive statistics for cluster-level unit values while Table 2 presents descriptive statistics for budget shares. Descriptive statistics are presented for the most recent three quinquennial NSS rounds (NSS 50, 55 and 61) and for the most recent 'thin' NSS round (NSS 64). Unit values in Table 1 have not been adjusted for inflation. The difference in unit values between bidis and cigarettes is substantial across all NSS rounds. For example, in 2007/08, a bundle of 10 bidis would costs about 2 Rs while a pack of 10 cigarettes would cost about 20 Rs. Table 1 shows clearly the very small number of unit value data points per village/urban blocks. The proportion of household that reported purchasing bidis has decreased substantially in both rural and urban areas between 1993/94 and 2007/08 (Table 2). The proportion of household who reported purchasing cigarettes decreased between 1993/94 and 2004/05 and then increased quite markedly between 2004/05 and 2007/08. Changes between 1993/94 and 2007/08 differ markedly between urban/rural strata. For example, the proportion of

\footnotetext{
${ }^{13}$ India is a union of twenty-eight states and seven union territories. Consumption of alcohol is prohibited in Lakshadweep, the smallest union territory of India. As none of the households surveyed in Lakshadweep report consuming country liquor, they are removed from the analyses.
} 
urban household who reported purchasing cigarettes decreased slightly between 1993/94 and 2007/08 while among rural households it increased by more than $20 \%$. These trends are more or less in keeping with individual-level smoking trends between 1998 and 2010 (Joseph et al., 2011).

We first present the results for each individual NSS quinquennial rounds using Deaton's approach of two-equation system of budget shares and unit values. We then present the results of our pooled analysis.

\section{Single cross-sectional surveys: NSS quinquennial rounds}

Table 3 presents the results of the within-cluster regressions for unit values and budget shares. The coefficients of total household expenditures (in natural log) in the unit value regressions represent expenditure elasticities of quality. For example, a doubling of total expenditure would raise the price paid for cigarettes by about 13.5 to $20 \%$. In the within-cluster regressions for budget shares, a positive coefficient indicates the share of the budget spent on the good rises with total expenditure. Total expenditure elasticity (i.e. the sum of expenditure elasticity of quantity and quality) varies across tobacco products in size but not in direction. It is positive for bidis and cigarettes suggesting that an increase in total household expenditure would result in an increase in expenditure of smoking tobacco. Estimates of total expenditure elasticity do not vary appreciably between NSS rounds nor do they vary by specifications (i.e. using village/urban block vs. district as clusters). The last two columns of Table 3 present the impact of a $6 \%$ 
increase in total household expenditures on quality and budget shares. ${ }^{14}$ Our results suggest, for example, that a $6 \%$ increase in total household expenditures in 2004/05 would have increased the price paid for a bundle of bidis (25) by about 0.04-0.07 Rs, for pack of cigarettes (10) by about 1.2-1.6 Rs and for country liquor (1 litre) by about 2.0-5.9 Rs. Similarly, a 6\% increase in total household expenditures would be expected to increase budget shares (among consuming households) by about $1 \%$ for bidis, 3-4\% for cigarettes and 2-4\% for country liquor.

Table 4 presents the own-price elasticities for two smoking tobacco products - bidi and cigarette - together with bootstrapped standard errors (SE). The SE are obtained using Deaton's approach from 1000 replications of the bootstrap using the cluster-level data and are defined as half the length of the interval around the bootstrap mean that contains 0.638 (the fraction of a normal random variable within two standard deviations of the mean) of the bootstrap replications (Deaton, 1997).

On the whole, we find statistically significant and fairly large own-price elasticities for bidis. When treating villages/urban blocks as clusters, we find statistically significant own-price elasticities for bidis with estimates ranging from about -0.5 to -1.0 . When treating districts as clusters, we find similar own-price elasticities for bidis using NSS 55 but not NSS 61. We do not find that urban and rural household respond differently to changes in bidi prices. Our sensitivity checks suggest that our estimates of own-price elasticities for bidis are robust to alternative specifications (Table A2).

\footnotetext{
${ }^{14} 6 \%$ represents approximately the average annual increase in inflation-adjusted total household expenditures during the 2000s. It also represents the IMF's forecast of India's inflation-adjusted annual GDP per capita growth 20112016 (International Monetary Fund, 2011)
} 
When treating villages/urban blocks as clusters, we find no evidence that own-price elasticities for cigarettes are statistically different from zero. When treating districts as clusters, however, we find statistically significant and large own-price elasticities for cigarettes. We find that urban households may be more responsive than rural households to changes in cigarette prices. On the whole, however, we do not find that our estimates of own-price elasticities for cigarettes are robust to alternative specifications (Table A2).

Tables 5.1 and 5.2 present the cross-price elasticities. On the whole, we find little evidence that the cross-price effects are significantly different from zero. If anything, these results suggest substitutability between bidis, cigarettes and country liquor among urban households.

\section{Pooled analysis: repeated cross-sectional surveys}

Table 6 presents estimates of own-price elasticities obtained from the pooled analyses. The top panel presents results for regressions where we average unit values by cluster over all households. The bottom panel presents results for regressions where unit values have been averaged only over households under examination. We find negative and statistically significant own-price elasticities with fairly large effect sizes for bidis and cigarettes.

We examined households’ price responsiveness across urban/rural strata and across socioeconomic status (SES) using three measures: 1) household income (proxied by total household expenditures, bottom three quintiles vs. top two quintiles); 2) household head's education ( $\leq$ primary vs. > primary); and, 3) social groups (scheduled tribe, scheduled caste and other backward class vs. other social groups). We find own-price elasticities for bidis vary across 
urban-rural strata and household income: rural households (-0.95 vs. -0.88,-0.87) and households with lower income $(-0.95$ vs. $-0.86,-0.89)$ tend to be more responsive to changes in bidi prices. These differences, however, are generally not statistically significant. We do not find that ownprice elasticities for bidis vary across education or social group categories. Our estimates of ownprice elasticities for bidis are robust across alternative specifications. We find consistent evidence that households from lower social groups tend to be more responsive to changes in cigarette prices $(-1.13,-1.07$ vs. $-0.91,-0.90)$. We also find some evidence that own-price elasticities for cigarettes may vary across urban-rural strata, household income and education but only when we average unit values by cluster over all households (Table 6, top panel).

Table 7 and Figures 1-4 present cross-price elasticities obtained from the pooled analyses. On the whole, we do not find that changes in the prices of cigarettes or country liquor have any impact on the demand for bidis. We find statistically significant cross-price elasticities between the demand for cigarettes and the prices of country liquor: a 10\% increase in the price of country liquor would increase the demand for cigarettes by about $1.2 \%$. We find statistically significant cross-price elasticities between the demand for cigarettes and the prices of bidis only when using unit values that have been averaged only over households under examination. These estimates of cross-price elasticities suggest some substitutability between cigarettes and bidis among rural households and among lower SES households and some complementarity between cigarettes and bidis among higher SES households. Put differently, an increase in bidi prices would increase the demand for cigarettes among rural households and among low SES households and decrease the demand for cigarettes among high SES households. These differences, however, are generally not statistically significant. 


\section{DISCUSSION}

Our analyses of single and repeated cross-sections yield own-price elasticity for bidis that are roughly in keeping with existing evidence. We find that a 10\% increase in bidi prices would reduce the demand for bidis by about 6 to 9.5\%. We find, however, that own-price elasticity for cigarettes in India is substantially larger than previously thought. Our estimates suggest that cigarette users are at least as responsive as bidi users to price changes. On the whole, our analyses suggest that low SES households are likely more responsive to price changes than high SES households.

Our analyses uncovers important and policy-relevant cross-prices effects. We find that cigarettes and country liquor are likely substitutes and that the substitutability tends to be larger among lower SES households. We also find that cross-price elasticities between bidis and cigarettes may vary by SES and urban/rural strata. Our findings suggest there may be some substitutability between cigarettes and bidis among rural and low-SES households and some complementarity between cigarettes and bidis among higher SES households.

Our study extends existing research in a number of ways. First, in addition to NSS 50 and 55, we use the most recent quinquennial round, NSS 61. Second, in addition to the traditional approach that treats villages and urban blocks as clusters, we also treat districts as clusters. As discussed earlier, we feel that India’s low household cigarette smoking prevalence warrants experimenting with such an approach. Third, we pool nearly a decade of data combining both 'thick' (i.e. quinquennial) and ‘thin' rounds of the National Sample Survey. This approach allows us to 
examine price responsiveness across urban/rural strata and SES categories. In doing so, we use two approaches to estimate our measure of price. First, we average unit values by cluster and include only households under examination. This approach has the advantage of better reflecting market prices in the relevant geographic area. For example, it will likely better reflect prices faced by households living in urban or rural areas or prices faced by low-SES households (inasmuch as they live in similar geographic areas). Two issues are worth noting: 1) to the extent this price measure is based on small numbers, the prices will tend to get closer to individual selfreported prices which may bias the elasticity estimates away from zero given the increased endogeneity of price; and 2) to the extent that the sample used to construct the price measure is non-representative, increased measurement error may bias elasticity estimates towards zero. Second, we estimate models where we average unit values by cluster over all households. This approach has the advantage of utilising the full sample of unit values and may attenuate measurement error. However, it may bias elasticity estimates towards zero if the price measure is not reflective of prices households face. We do not find that own-price elasticities for bidis differ across specifications. We do find, however, that our estimates of own-price elasticities for cigarettes from models where we average unit values by cluster over all households tend to be higher for rural and low-SES households,

There are some limitations that merit discussion. Using three sets of price data (unit values, market prices and household opinions) in Papua New Guinea, Gibson and Rozelle (2005) find that there are substantial biases when unit values are used as a proxy for market price, even when sophisticated correction methods such as Deaton’s are applied. Niimi (2005) uses unit values and market prices to estimate a food demand system and finds that Deaton’s method generates 
materially different price elasticities from those estimated with market prices. India’s Labour Bureau compiles consumer price indices for industrial workers (CPI-IW) on a monthly basis, using retail prices collected from 261 markets in 76 centres. The Labour Bureau also compiles consumer price indices for agricultural labourers and rural labourers (CPI-AL/RL) on a monthly basis from fixed markets in 600 sample villages in 20 states. CPI-IW data are publicly available at the centre-level while CPI-AL/RL are available at the market-level. An obvious avenue for further research is to link market prices for bidis, cigarettes and country liquor from both CPI-IW and CPI-AL/RL to NSS data. Household-level data, unlike individual-level data, do not allow to examine price responsiveness by individual characteristics such as sex or age. Household-level data also renders the interpretation of cross-price effects less evident. This is an important limitation of our analyses as smoking patterns vary considerably by type (e.g. bidi, cigarette, smokeless), age and sex in India. The recently available 2009/10 Global Adult Tobacco Survey will provide an excellent opportunity to examine further the impact of prices on tobacco use in India (Government of India, 2010).

Findings from this study provide additional evidence of the effectiveness of tobacco prices at reducing tobacco use. Increasing the price of smoking tobacco products, in addition to leading to reduced tobacco use, can be expected to increase tax revenue. We find own-price elasticities as high as $|-1|$ that are substantially larger than the consensus estimate for high-income countries of about |-0.4|. Even so, nearly all practicable tax increases would generate increased revenues (Warner, 2000). In India, bidi and cigarette taxes constitute only a fraction of total price (about $40 \%$ for cigarettes and nearly nil for bidis at the central level). For example, assuming all taxes (at central and state level) constitute half of the price of a pack of cigarettes, a doubling of the tax 
rate would increase retail price by only $50 \%$. As pointed out by Warner, tobacco users would have to be extraordinarily price sensitive for consumption declines to exceed the rate of increase in tax (Warner, 2000), far more so than found in this study. On the whole, our findings suggest that using the tax system to increase the prices of bidis and cigarettes would lead to a significant and substantial reduction in tobacco use while increasing government tax revenue. 


\section{REFERENCES}

Arunatilake N. An Economic Analysis of Tobacco Demand in Sri Lanka. Sri Lanka Economic Journal 2002; 3: 96-120.

Bonu S, Rani M, Peters DH, Jha P, Nguyen SN. Does use of tobacco or alcohol contribute to impoverishment from hospitalization costs in India? Health Policy Plan 2005; 20: 41-9. doi: 10.1093/heapol/czi005

Chaloupka FJ, Warner KE. The Economics of Smoking. In AJ Culyer and JP Newhouse eds. Handbook of Health Economics. Amsterdam: Elsevier Science, North-Holland, 2000, pp 1539-627.

Chowdhury AN, Ramakrishna J, Chakraborty AK, Weiss MG. Cultural context and impact of alcohol use in the Sundarban Delta, West Bengal, India. Social Science \& Medicine 2006; 63: 722-31. doi:

10.1016/j.socscimed.2006.02.006

Cox TL, Wohlgenant MK. Prices and Quality Effects in Cross-Sectional Demand Analysis. American Journal of Agricultural Economics 1986; 68: 908-19.

Deaton A. Household Survey Data and Pricing Policies in Developing Countries. World Bank Economic Review 1989; 3: 183-210.

Deaton A. Price elasticities from survey data: extensions and Indonesian results. Journal of Econometrics 1990; 44: 281-309.

Deaton A. The Analysis of Household Surveys: A Microeconometric Approach to Development Policy. Baltimore: The Johns Hopkins University Press, 1997.

Deaton A, Tarozzi A. Prices and poverty in India. Princeton: Princeton University, Woodrow Wilson School of Public and International Affairs, 2000.

Gajalakshmi V, Peto R, Kanaka TS, Jha P. Smoking and mortality from tuberculosis and other diseases in India: retrospective study of 43000 adult male deaths and 35000 controls. Lancet 2003; 362: 507-15. doi: 10.1016/S0140-6736(03)14109-8

Gibson J, Rozelle S. Prices and unit values in poverty measurement and tax reform analysis. The World Bank Economic Review 2005; 19: 69-97.

Government of India. Concepts and Definitions Used in NSS. New Delhi: National Sample Survey Organisation, Ministry of Statistics \& Programme Implementation, Government of India, 2001.

Government of India. Global Adult Tobacco Survey India (GATS India), 2009-2010. Mumbai: International Institute for Population Sciences (IIPS) and Ministry of Health and Family Welfare, 2010.

Guindon GE, Perucic A-M, Boisclair D. Higher tobacco prices and Taxes in South-East Asia: an effective tool to reduce tobacco use, save lives and increase government revenue. HNP Discussion Paper Economics of Tobacco Control Paper No 11. Washington: The World Bank, 2003.

Gupta PC, Saxena S, Pednekar MS, Maulik PK. Alcohol consumption among middle-aged and elderly men: a community study from western India. Alcohol and Alcoholism 2003; 38: 327-31. doi: 10.1093/alcalc/agg077 
International Agency for Research on Cancer. IARC Handbooks of Cancer Prevention: Tobacco Control. Volume 14. Effectiveness of Price and Tax Policies for Control of Tobacco. Lyon: International Agency for Research on Cancer, 2011.

International Monetary Fund. World Economic Outlook Database. September 2011 Edition. International Monetary Fund, 2011.

Jha P, Chaloupka FJ. Curbing the epidemic: governments and the economics of tobacco control. Washington: The World Bank, 1999.

Jha P, Guindon E, Joseph RA, Nandi A, John RM, Rao K, Chaloupka FJ, Kaur J, Gupta PC, Rao MG. A rational taxation system of bidis and cigarettes to reduce smoking deaths in India. EPW Economic \& Political Weekly 2011; XLVI: 44-51.

Jha P, Jacob B, Gajalakshmi V, Gupta PC, Dhingra N, Kumar R, Sinha DN, Dikshit RP, Parida DK, Kamadod R, Boreham J, Peto R. A nationally representative case-control study of smoking and death in India. N Engl J Med 2008; 358: 1137-47. doi: 10.1056/NEJMsa0707719

John RM. Price Elasticity Estimates for Tobacco and Other Addictive Goods in India. Working Paper Series No. WP-2005-003. Mumbai: Indira Gandhi Institute of Development Research, 2005.

John RM. Price elasticity estimates for tobacco products in India. Health Policy Plan 2008a; 23: 200-9. doi: 10.1093/heapol/czn007

John RM, Sung HY, Max W. Economic cost of tobacco use in India, 2004. Tob Control 2009; 18: 13843. doi: 10.1136/tc.2008.027466

John S. History and Culture of Bidis in India: Production, Employment, Marketing and Regulations. In PC Gupta and S Asma eds. Bidi Smoking and Public Health and Public Health. New Delhi: Ministry of Health and Family Welfare, Government of India, 2008b, pp 1-12.

Joseph RA, Gupta PC, Kaur J, Ram F, Sinha DN, Dixit R, Palipudi K, Pezzack B, Asma S, Jha P. Smoking in India: Trend Analysis from 1998-2010. Working Paper. Toronto: Centre for Global Health Research, St. Michael's Hospital, University of Toronto, 2011.

Karki YB, Pant KD, Pande BR. A Study on the Economics of Tobacco in Nepal. HNP Discussion Paper Series. Economics of Tobacco Control Paper No. 13. Washington: The World Bank, 2003.

Mushtaq N, Mushtaq S, Beebe LA. Economics of tobacco control in Pakistan: estimating elasticities of cigarette demand. Tob Control 2011. doi: 10.1136/tc.2010.040048

Nargis N, Ruthbah UH, Fong GT. Taxation of Tobacco Products in Bangladesh: Findings from the 2009 ITC Bangladesh Survey. ITC Project Working Paper Series. Waterloo: University of Waterloo, 2010.

Niimi Y. An Analysis of Household Responses to Price Shocks in Vietnam: Can Unit Values Substitute for Market Prices? Sussex: Poverty Research Unit at Sussex, University of Sussex, 2005.

Prais SJ, Houthakker HS. The Analysis of Family Budgets. Cambridge: Cambridge University Press, 1955. 
Rani M, Bonu S, Jha P, Nguyen SN, Jamjoum L. Tobacco use in India: prevalence and predictors of smoking and chewing in a national cross sectional household survey. Tob Control 2003; 12: e4.

Warner KE. The economics of tobacco: myths and realities. Tob Control 2000; 9: 78-89. 
Table 1. Descriptive statistics for cluster-level unit values

\begin{tabular}{|c|c|c|c|c|c|c|c|c|}
\hline & \multicolumn{4}{|c|}{ Unit value, RS } & \multicolumn{2}{|c|}{$\begin{array}{c}\text { No. of clusters } \\
\text { with data }\end{array}$} & \multicolumn{2}{|c|}{$\begin{array}{c}\text { Mean no. of obs. } \\
\text { per cluster }\end{array}$} \\
\hline & $\mathrm{n}$ & Mean & Median & Std. Dev. & Villages & Districts & Villages & Districts \\
\hline \multicolumn{9}{|l|}{ - NSS 50 (1993/94) } \\
\hline Bidi (1 stick) & 42,033 & 0.09 & 0.08 & 0.03 & 9,623 & n.a. & 4.4 & n.a. \\
\hline Cigarette (1 stick) & 10,138 & 0.67 & 0.60 & 0.27 & 4,935 & n.a. & 2.1 & n.a. \\
\hline Country liquor (1 litre) & 8,910 & 37.1 & 32.0 & 31.5 & 3,815 & n.a. & 2.3 & n.a. \\
\hline \multicolumn{9}{|l|}{ - NSS 55 (1999/00) } \\
\hline Bidi (1 stick) & 31,567 & 0.15 & 0.13 & 0.15 & 7,686 & 478 & 4.1 & 66.0 \\
\hline Cigarette (1 stick) & 8,794 & 1.33 & 1.00 & 1.54 & 4,214 & 445 & 2.1 & 19.8 \\
\hline Country liquor (1 litre) & 8,270 & 55.7 & 40.0 & 53.4 & 3,512 & 441 & 2.4 & 18.8 \\
\hline \multicolumn{9}{|l|}{ - NSS $61(2004 / 05)$} \\
\hline Bidi (1 stick) & 32,751 & 0.17 & 0.16 & 0.10 & 9,232 & 478 & 3.5 & 68.5 \\
\hline Cigarette (1 stick) & 9,153 & 1.49 & 1.30 & 1.42 & 4,779 & 461 & 1.9 & 19.9 \\
\hline Country liquor (1 litre) & 10,462 & 63.2 & 41.3 & 61.7 & 4,638 & 455 & 2.3 & 23.0 \\
\hline \multicolumn{9}{|l|}{ - NSS 64 (2007/08) } \\
\hline Bidi (1 stick) & 10,660 & 0.20 & 0.23 & 0.09 & 5,726 & 449 & 1.9 & 23.7 \\
\hline Cigarette (1 stick) & 4,081 & 1.94 & 2.00 & 1.02 & 2,758 & 403 & 1.5 & 10.1 \\
\hline Country liquor (1 litre) & 3,679 & 70.1 & 50.0 & 61.7 & 2,365 & 395 & 1.6 & 9.3 \\
\hline \multicolumn{9}{|c|}{$\begin{array}{l}\text { Note: } \text { n.a. = not applicable; NSS 50: Total number of obvs. =114,864; Total number of clusters: villages/urban } \\
\text { blocks = 11,601; NSS 55: Total number of obvs. = 114,350; Total number of clusters: villages/urban blocks = } \\
\text { 10,014; districts = 483; NSS 61: Total number of obvs. = 123,655; Total number of clusters: villages/urban } \\
\text { blocks = 12,500; districts = 487; NSS 64: Total number of obvs. = 46,196; Total number of clusters: } \\
\text { villages/urban blocks = 11,683; districts = 469. }\end{array}$} \\
\hline
\end{tabular}


Table 2. Descriptive statistics for budget shares

\begin{tabular}{|c|c|c|c|c|c|c|c|c|c|}
\hline & \multicolumn{3}{|c|}{$\%$ consuming } & \multicolumn{3}{|c|}{ Share, total } & \multicolumn{3}{|c|}{ Share, consuming hh } \\
\hline & All & Rural & Urban & All & Rural & Urban & All & Rural & Urban \\
\hline \multicolumn{10}{|c|}{ - NSS 50 (1993/94) } \\
\hline Bidis & 0.367 & 0.439 & 0.258 & 0.011 & 0.014 & 0.008 & 0.031 & 0.031 & 0.031 \\
\hline Cigarettes & 0.089 & 0.060 & 0.134 & 0.003 & 0.002 & 0.005 & 0.037 & 0.031 & 0.040 \\
\hline Country liquor & 0.079 & 0.095 & 0.054 & 0.004 & 0.005 & 0.003 & 0.053 & 0.050 & 0.061 \\
\hline \multicolumn{10}{|c|}{ - NSS 55 (1999/00) } \\
\hline Bidis & 0.276 & 0.344 & 0.184 & 0.008 & 0.010 & 0.005 & 0.028 & 0.028 & 0.026 \\
\hline Cigarettes & 0.077 & 0.053 & 0.110 & 0.003 & 0.002 & 0.004 & 0.037 & 0.035 & 0.038 \\
\hline Country liquor & 0.072 & 0.088 & 0.051 & 0.004 & 0.004 & 0.003 & 0.053 & 0.050 & 0.060 \\
\hline \multicolumn{10}{|c|}{ - NSS 61 (2004/05) } \\
\hline Bidis & 0.265 & 0.312 & 0.183 & 0.007 & 0.009 & 0.005 & 0.028 & 0.029 & 0.027 \\
\hline Cigarettes & 0.074 & 0.061 & 0.096 & 0.002 & 0.002 & 0.004 & 0.034 & 0.031 & 0.037 \\
\hline Country liquor & 0.085 & 0.100 & 0.058 & 0.004 & 0.005 & 0.003 & 0.048 & 0.046 & 0.053 \\
\hline \multicolumn{10}{|c|}{ - NSS 64 (2007/08) } \\
\hline Bidis & 0.231 & 0.284 & 0.127 & 0.005 & 0.006 & 0.002 & 0.022 & 0.022 & 0.020 \\
\hline Cigarettes & 0.088 & 0.073 & 0.117 & 0.003 & 0.002 & 0.004 & 0.030 & 0.028 & 0.033 \\
\hline Country liquor & 0.080 & 0.095 & 0.050 & 0.003 & 0.004 & 0.002 & 0.040 & 0.038 & 0.044 \\
\hline
\end{tabular}


Table 3. Within-cluster regressions for unit values and budget shares

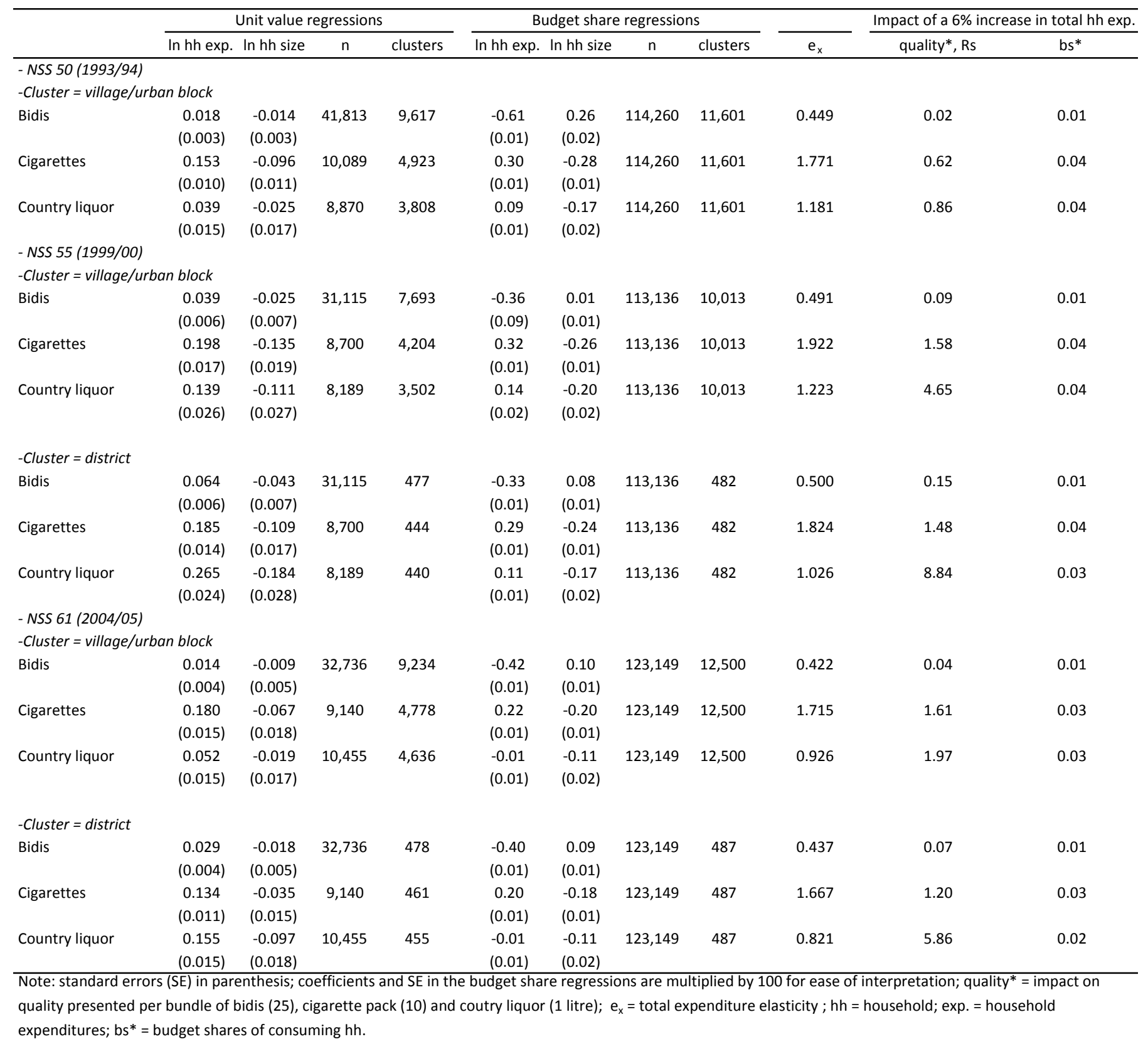


Table 4. Own-price elasticities -single cross-sectional surveys

\begin{tabular}{|c|c|c|c|c|c|c|}
\hline \multicolumn{7}{|l|}{ Specification } \\
\hline Clusters: & \multicolumn{3}{|c|}{ Village/urban block } & \multicolumn{3}{|c|}{ District } \\
\hline Region dummies: & \multicolumn{3}{|c|}{ NSS regions } & \multicolumn{3}{|c|}{ Regions } \\
\hline Time dummies: & \multicolumn{3}{|c|}{ Quarters } & \multicolumn{3}{|c|}{ Quarters } \\
\hline \multirow[t]{2}{*}{ Outliers: } & \multicolumn{3}{|c|}{$5 \mathrm{SD}$} & \multicolumn{3}{|c|}{$5 \mathrm{SD}$} \\
\hline & All & Rural & Urban & All & Rural & Urban \\
\hline \multicolumn{7}{|l|}{ - NSS 50 (1993/94) } \\
\hline Bidis & $\begin{array}{l}-0.77 \\
(0.05)\end{array}$ & $\begin{array}{c}-0.74 \\
(0.06)\end{array}$ & $\begin{array}{c}-0.74 \\
(0.09)\end{array}$ & n.a. & n.a. & n.a. \\
\hline Cigarettes & $\begin{array}{c}0.64 \\
(0.33)\end{array}$ & $\begin{array}{c}0.56 \\
(0.62)\end{array}$ & $\begin{array}{c}0.27 \\
(0.35)\end{array}$ & n.a. & n.a. & n.a. \\
\hline \multicolumn{7}{|l|}{ - NSS 55 (1999/00) } \\
\hline Bidis & $\begin{array}{l}-1.00 \\
(0.03)\end{array}$ & $\begin{array}{l}-0.97 \\
(0.03)\end{array}$ & $\begin{array}{l}-0.91 \\
(0.08)\end{array}$ & $\begin{array}{l}\mathbf{- 1 . 2 6} \\
(0.13)\end{array}$ & $\begin{array}{l}-1.14 \\
(0.15)\end{array}$ & $\begin{array}{l}-1.15 \\
(0.36)\end{array}$ \\
\hline Cigarettes & $\begin{array}{c}-0.08 \\
(0.23)\end{array}$ & $\begin{array}{c}0.31 \\
(0.48)\end{array}$ & $\begin{array}{c}-0.28 \\
(0.32)\end{array}$ & $\begin{array}{l}-1.32 \\
(0.24)\end{array}$ & $\begin{array}{l}-0.81 \\
(0.28)\end{array}$ & $\begin{array}{l}-2.19 \\
(1.08)\end{array}$ \\
\hline \multicolumn{7}{|l|}{ - NSS 61 (2004/05) } \\
\hline Bidis & $\begin{array}{l}-0.61 \\
(0.06)\end{array}$ & $\begin{array}{c}-0.61 \\
(0.07)\end{array}$ & $\begin{array}{l}-0.48 \\
(0.15)\end{array}$ & $\begin{array}{c}-0.28 \\
(0.26)\end{array}$ & $\begin{array}{l}-0.25 \\
(0.23)\end{array}$ & $\begin{array}{c}-0.65 \\
(0.34)\end{array}$ \\
\hline Cigarettes & $\begin{array}{l}-0.06 \\
(0.23)\end{array}$ & $\begin{array}{c}0.15 \\
(0.35)\end{array}$ & $\begin{array}{l}-0.30 \\
(0.32)\end{array}$ & $\begin{array}{l}\mathbf{- 1 . 3 1} \\
(0.22)\end{array}$ & $\begin{array}{l}-1.16 \\
(0.25)\end{array}$ & $\begin{array}{l}-1.28 \\
(0.34)\end{array}$ \\
\hline
\end{tabular}

Note: n.a. = not applicable; Estimates shown in bold are greater than twice their bootstrapped standard errors (SE). See text for description of bootstrapped SE; 5 SD = unit values whose logarithms lied more than $5(2.5)$ standard deviations from the mean were removed. 
Table 5.1. Cross-price elasticities between the demand for bidis and the prices of cigarette and country liquor - single cross-sectional surveys

\begin{tabular}{|c|c|c|c|c|c|c|}
\hline \multirow[t]{2}{*}{ Specification (cluster) } & \multicolumn{3}{|c|}{ Village/urban block } & \multicolumn{3}{|c|}{ District } \\
\hline & All & Rural & Urban & All & Rural & Urban \\
\hline \multicolumn{7}{|l|}{ - NSS 50 (1993/94) } \\
\hline \multirow[t]{2}{*}{ Cigarettes } & 0.055 & 0.073 & 0.023 & n.a & n.a & n.a \\
\hline & $(0.044)$ & $(0.062)$ & $(0.086)$ & n.a & n.a & n.a \\
\hline \multirow[t]{2}{*}{ Country liquor } & 0.089 & 0.101 & 0.059 & n.a & n.a & n.a \\
\hline & $(0.023)$ & $(0.025)$ & $(0.065)$ & n.a & n.a & n.a \\
\hline \multicolumn{7}{|l|}{ - NSS 55 (1999/00) } \\
\hline \multirow[t]{2}{*}{ Cigarettes } & -0.049 & -0.078 & 0.000 & 0.025 & -0.083 & 0.420 \\
\hline & $(0.033)$ & $(0.045)$ & $(0.088)$ & $(0.103)$ & $(0.098)$ & (0.394) \\
\hline \multirow[t]{2}{*}{ Country liquor } & 0.018 & 0.015 & 0.070 & 0.097 & 0.072 & 0.239 \\
\hline & $(0.021)$ & $(0.020)$ & $(0.064)$ & $(0.064)$ & $(0.055)$ & $(0.337)$ \\
\hline \multicolumn{7}{|l|}{ - NSS 61 (2004/05) } \\
\hline \multirow[t]{2}{*}{ Cigarettes } & -0.023 & 0.009 & -0.110 & 0.244 & 0.110 & 0.442 \\
\hline & $(0.045)$ & $(0.060)$ & $(0.100)$ & (0.129) & $(0.141)$ & (0.166) \\
\hline \multirow[t]{2}{*}{ Country liquor } & 0.034 & 0.037 & 0.137 & 0.070 & 0.058 & 0.246 \\
\hline & $(0.027)$ & $(0.029)$ & $(0.060)$ & $(0.075)$ & $(0.077)$ & (0.099) \\
\hline
\end{tabular}

Note: n.a. = not applicable; Estimates shown in bold are greater than twice their bootstrapped standard errors (SE). See text for descrption of bootstrapped SE. 
Table 5.2. Cross-price elasticities between the demand for cigarettes and the prices of bidi and country liquor - single cross-sectional surveys

\begin{tabular}{|c|c|c|c|c|c|c|}
\hline \multirow{2}{*}{ Specification (cluster) } & \multicolumn{3}{|c|}{ Village/urban block } & \multicolumn{3}{|c|}{ District } \\
\hline & All & Rural & Urban & All & Rural & Urban \\
\hline \multicolumn{7}{|l|}{ - NSS 50 (1993/94) } \\
\hline \multirow[t]{2}{*}{ Bidi } & 0.182 & 0.525 & 0.025 & n.a & n.a & n.a \\
\hline & $(0.163)$ & $(0.466)$ & $(0.133)$ & n.a & n.a & n.a \\
\hline \multirow[t]{2}{*}{ Country liquor } & 0.102 & 0.015 & 0.203 & n.a & n.a & n.a \\
\hline & $(0.081)$ & $(0.145)$ & $(0.130)$ & n.a & n.a & n.a \\
\hline \multicolumn{7}{|l|}{ - NSS 55 (1999/00) } \\
\hline \multirow[t]{2}{*}{ Bidi } & -0.146 & -0.429 & -0.007 & 0.056 & -0.436 & 0.428 \\
\hline & $(0.090)$ & $(0.234)$ & $(0.098)$ & $(0.271)$ & $(0.498)$ & $(0.406)$ \\
\hline \multirow[t]{2}{*}{ Country liquor } & 0.042 & 0.106 & -0.061 & 0.053 & 0.207 & -0.159 \\
\hline & $(0.061)$ & $(0.108)$ & $(0.132)$ & $(0.090)$ & $(0.153)$ & (0.429) \\
\hline \multicolumn{7}{|l|}{ - NSS 61 (2004/05) } \\
\hline \multirow[t]{2}{*}{ Bidi } & -0.086 & 0.028 & -0.165 & 0.729 & 0.519 & 0.596 \\
\hline & $(0.144)$ & $(0.303)$ & $(0.144)$ & $(0.391)$ & $(0.681)$ & $(0.225)$ \\
\hline \multirow[t]{2}{*}{ Country liquor } & -0.035 & 0.024 & -0.088 & 0.212 & 0.222 & 0.101 \\
\hline & $(0.075)$ & $(0.139)$ & $(0.093)$ & $(0.095)$ & (0.148) & $(0.100)$ \\
\hline
\end{tabular}

Note: n.a. = not applicable; Estimates shown in bold are greater than twice their bootstrapped standard errors (SE). See text for descrption of bootstrapped SE. 
Table 6. Own-price elasticities -pooled analyses, 1999/00 - 2007/08

\begin{tabular}{|c|c|c|c|c|c|c|c|c|c|}
\hline & \multirow[b]{2}{*}{ All } & \multicolumn{2}{|c|}{ Rural/urban } & \multicolumn{2}{|c|}{ Expenditure quintiles } & \multicolumn{2}{|c|}{ Education } & \multicolumn{2}{|c|}{ Social Groups } \\
\hline & & Rural & Urban & low (q1-q3) & high (q4-q5) & $\leq$ primary & $>$ primary & $\begin{array}{c}\text { lower } \\
\text { caste/tribe }\end{array}$ & others \\
\hline \multicolumn{10}{|c|}{-Unit values averaged by cluster over all households } \\
\hline Bidis & $\begin{array}{l}-0.940 \\
(0.02)^{* * *}\end{array}$ & $\begin{array}{l}-0.950 \\
(0.02)^{* * *}\end{array}$ & $\begin{array}{l}-0.884 \\
(0.04)^{* * *}\end{array}$ & $\begin{array}{l}-0.950 \\
(0.02)^{* * *}\end{array}$ & $\begin{array}{l}-0.864 \\
(0.04)^{* * *}\end{array}$ & $\begin{array}{l}-0.920 \\
(0.02)^{* * *}\end{array}$ & $\begin{array}{l}-0.943 \\
(0.04)^{* * *}\end{array}$ & $\begin{array}{l}-0.935 \\
(0.02)^{* * *}\end{array}$ & $\begin{array}{l}-0.941 \\
(0.04)^{* * *}\end{array}$ \\
\hline Cigarettes & $\begin{array}{l}-1.026 \\
(0.03)^{* * *}\end{array}$ & $\begin{array}{l}-1.089 \\
(0.04)^{* * *}\end{array}$ & $\begin{array}{l}-1.027 \\
(0.04)^{* * *}\end{array}$ & $\begin{array}{l}-1.116 \\
(0.05)^{* * *}\end{array}$ & $\begin{array}{l}-0.993 \\
(0.03)^{* * *}\end{array}$ & $\begin{array}{l}-1.161 \\
(0.05)^{* * *}\end{array}$ & $\begin{array}{l}-0.950 \\
(0.04)^{* * *}\end{array}$ & $\begin{array}{l}-1.128 \\
(0.04)^{* * *}\end{array}$ & $\begin{array}{l}-0.907 \\
(0.05)^{* * *}\end{array}$ \\
\hline \multicolumn{10}{|c|}{-Unit values averaged by cluster only over households under examination } \\
\hline Bidis & $\begin{array}{l}-0.940 \\
(0.02)^{* * *}\end{array}$ & $\begin{array}{l}-0.946 \\
(0.02)^{* * *}\end{array}$ & $\begin{array}{l}-0.874 \\
(0.04)^{* * *}\end{array}$ & $\begin{array}{l}-0.954 \\
(0.03)^{* * *}\end{array}$ & $\begin{array}{l}-0.889 \\
(0.03)^{* * *}\end{array}$ & $\begin{array}{l}-0.909 \\
(0.03)^{* * *}\end{array}$ & $\begin{array}{l}-0.929 \\
(0.03)^{* * *}\end{array}$ & $\begin{array}{l}-0.942 \\
(0.02)^{* * *}\end{array}$ & $\begin{array}{l}-0.948 \\
(0.04)^{* * *}\end{array}$ \\
\hline Cigarettes & $\begin{array}{l}-1.026 \\
(0.03)^{* * *}\end{array}$ & $\begin{array}{l}-0.963 \\
(0.04)^{* * *}\end{array}$ & $\begin{array}{l}-1.019 \\
(0.04)^{* * *}\end{array}$ & $\begin{array}{l}-0.960 \\
(0.04)^{* * *}\end{array}$ & $\begin{array}{l}-1.021 \\
(0.04)^{* * *}\end{array}$ & $\begin{array}{l}-1.015 \\
(0.04)^{* * *}\end{array}$ & $\begin{array}{l}-1.011 \\
(0.04)^{* * *}\end{array}$ & $\begin{array}{l}-1.071 \\
(0.03)^{* * *}\end{array}$ & $\begin{array}{l}-0.895 \\
(0.05)^{* * *}\end{array}$ \\
\hline
\end{tabular}


Table 7. Cross-price elasticities -pooled analyses, 1999/00 - 2007/08

Table 7. Cross-price elasticities - pooled analyses, 1999/00 - 2007/08

\begin{tabular}{|c|c|c|c|c|c|c|c|c|c|}
\hline & \multirow[b]{2}{*}{ All } & \multicolumn{2}{|c|}{ Rural/urban } & \multicolumn{2}{|c|}{ Expenditure quintiles } & \multicolumn{2}{|c|}{ Education } & \multicolumn{2}{|c|}{ Social Groups } \\
\hline & & Rural & Urban & low (q1-q3) & high (q4-q5) & $\leq$ primary & $>$ primary & $\begin{array}{c}\text { lower } \\
\text { caste/tribe }\end{array}$ & others \\
\hline \multicolumn{10}{|c|}{ Cross-price elasticities between the demand for bidis and the prices of cigarette and country liquor } \\
\hline \multicolumn{10}{|c|}{-Unit values averaged by cluster over all households } \\
\hline \multirow[t]{2}{*}{ Cigarettes } & -0.021 & -0.023 & -0.004 & -0.023 & -0.038 & -0.028 & 0.016 & -0.020 & -0.033 \\
\hline & $(0.014)$ & $(0.015)$ & $(0.030)$ & $(0.016)$ & $(0.026)$ & $(0.015)^{*}$ & $(0.029)$ & $(0.016)$ & $(0.027)$ \\
\hline \multirow[t]{2}{*}{ Country liquor } & -0.002 & -0.003 & -0.006 & 0.001 & -0.014 & -0.013 & 0.043 & -0.003 & -0.002 \\
\hline & (0.009) & $(0.010)$ & (0.019) & $(0.011)$ & $(0.017)$ & $(0.010)$ & $(0.020)^{* *}$ & (0.011) & 0.018 \\
\hline \multicolumn{10}{|c|}{-Unit values averaged by cluster only over households under examination } \\
\hline \multirow[t]{2}{*}{ Cigarettes } & 0.000 & -0.034 & 0.012 & 0.005 & -0.033 & -0.021 & 0.017 & -0.043 & -0.046 \\
\hline & 0.000 & $(0.013)^{* *}$ & $(0.033)$ & $(0.014)$ & $(0.027)$ & $(0.014)$ & $(0.032)$ & $(0.015)^{* * *}$ & $(0.030)$ \\
\hline \multirow[t]{2}{*}{ Country liquor } & 0.000 & 0.009 & -0.004 & 0.001 & -0.013 & -0.003 & 0.009 & -0.006 & 0.009 \\
\hline & 0.000 & $(0.010)$ & (0.019) & $(0.011)$ & $(0.014)$ & $(0.012)$ & $(0.017)$ & (0.011) & $(0.015)$ \\
\hline \multicolumn{10}{|c|}{ Cross-price elasticities between the demand for cigarettes and the prices of bidi and country liquor } \\
\hline \multicolumn{10}{|c|}{-Unit values averaged by cluster over all households } \\
\hline \multirow[t]{2}{*}{ Bidis } & -0.029 & 0.011 & -0.012 & 0.040 & -0.075 & 0.040 & -0.052 & -0.018 & -0.014 \\
\hline & $(0.043)$ & $(0.068)$ & $(0.056)$ & $(0.075)$ & $(0.051)$ & $(0.075)$ & $(0.052)$ & $(0.056)$ & $(0.067)$ \\
\hline \multirow[t]{2}{*}{ Country liquor } & 0.118 & 0.090 & 0.141 & 0.128 & 0.120 & 0.147 & 0.094 & 0.112 & 0.125 \\
\hline & $(0.020)^{* * *}$ & $(0.030)^{* * *}$ & $(0.026)^{* * *}$ & $(0.033)^{* * *}$ & $(0.023)^{* * *}$ & $(0.033)^{* * *}$ & $(0.024)^{* * *}$ & $(0.025)^{* * *}$ & $(0.029)^{* * *}$ \\
\hline \multicolumn{10}{|c|}{-Unit values averaged by cluster only over households under examination } \\
\hline \multirow[t]{2}{*}{ Bidis } & -0.029 & 0.182 & -0.025 & 0.176 & -0.092 & 0.089 & -0.112 & -0.022 & -0.109 \\
\hline & $(0.043)$ & $(0.067)^{* * *}$ & $(0.052)$ & $(0.081)^{* *}$ & $(0.041)^{* *}$ & (0.078) & $(0.042)^{* * *}$ & $(0.056)$ & $(0.065)^{*}$ \\
\hline \multirow[t]{2}{*}{ Country liquor } & 0.118 & 0.087 & 0.101 & 0.176 & 0.110 & 0.151 & 0.047 & 0.112 & 0.084 \\
\hline & $(0.020)^{* * *}$ & $(0.029)^{* * *}$ & $(0.025)^{* * *}$ & $(0.033)^{* * *}$ & $(0.019)^{* * *}$ & $(0.034)^{* * *}$ & $(0.022)^{* *}$ & $(0.026)^{* * *}$ & $(0.025)^{* * *}$ \\
\hline
\end{tabular}

Note: Lower caste/tribe $=1$ ) scheduled tribe; 2 ) scheduled caste; and, 3) other backward class 
Figure 1. Cross-price elasticities between the demand for bidis and the prices of cigarettes

-Unit values averaged by cluster over all households

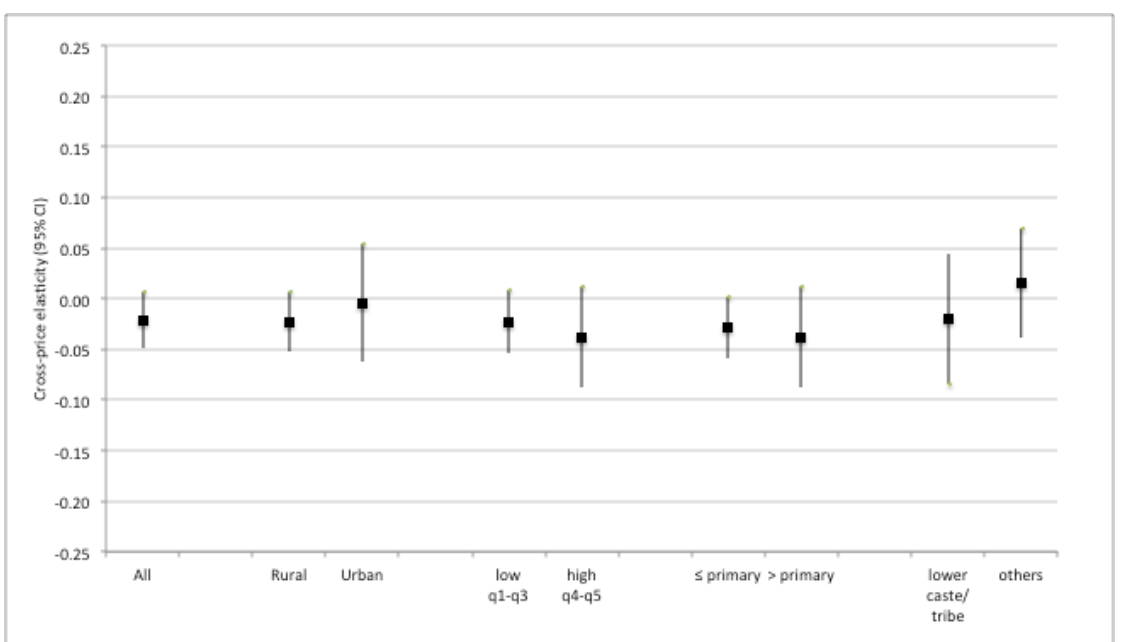

- Unit values averaged by cluster only over households under examination

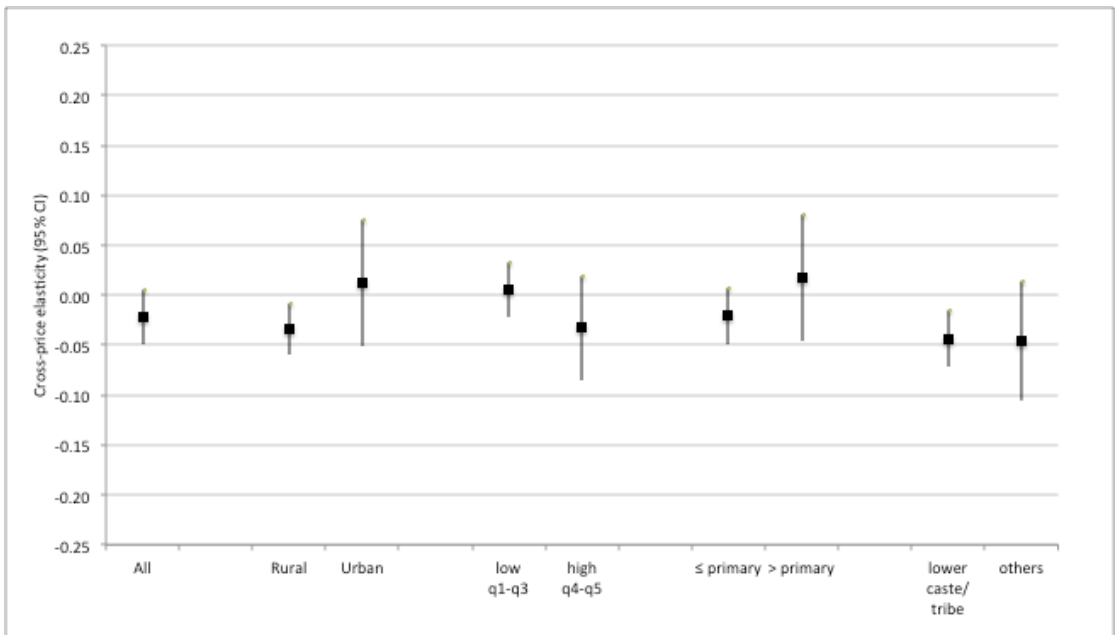

Figure 2. Cross-price elasticities between the demand for bidis and the prices of country liquor

-Unit values averaged by cluster over all households

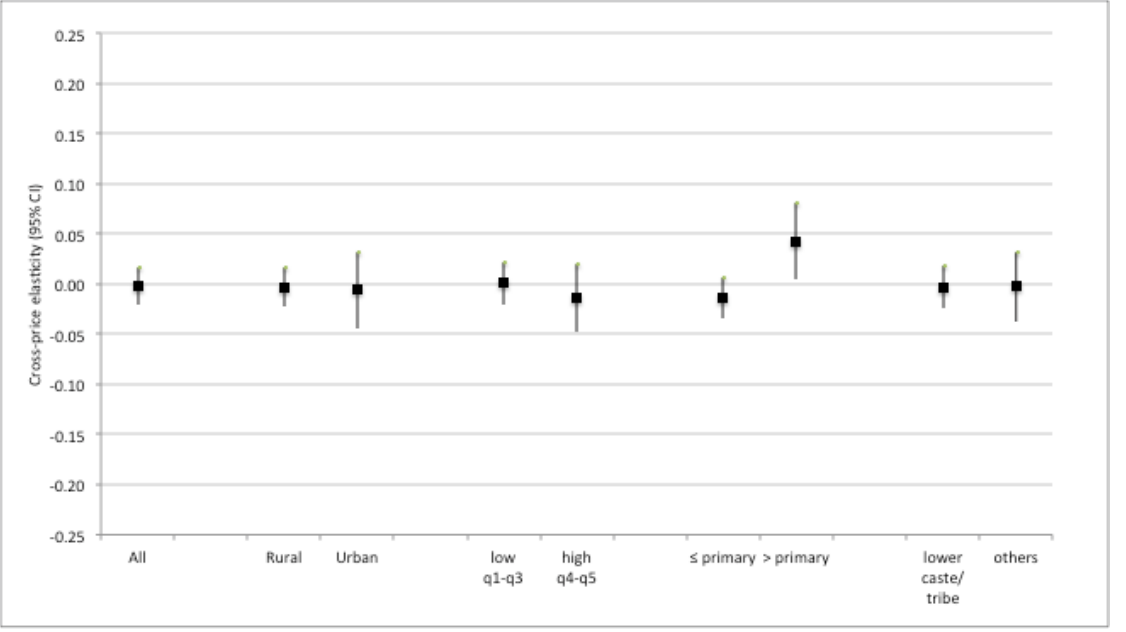

- Unit values averaged by cluster only over households under examination

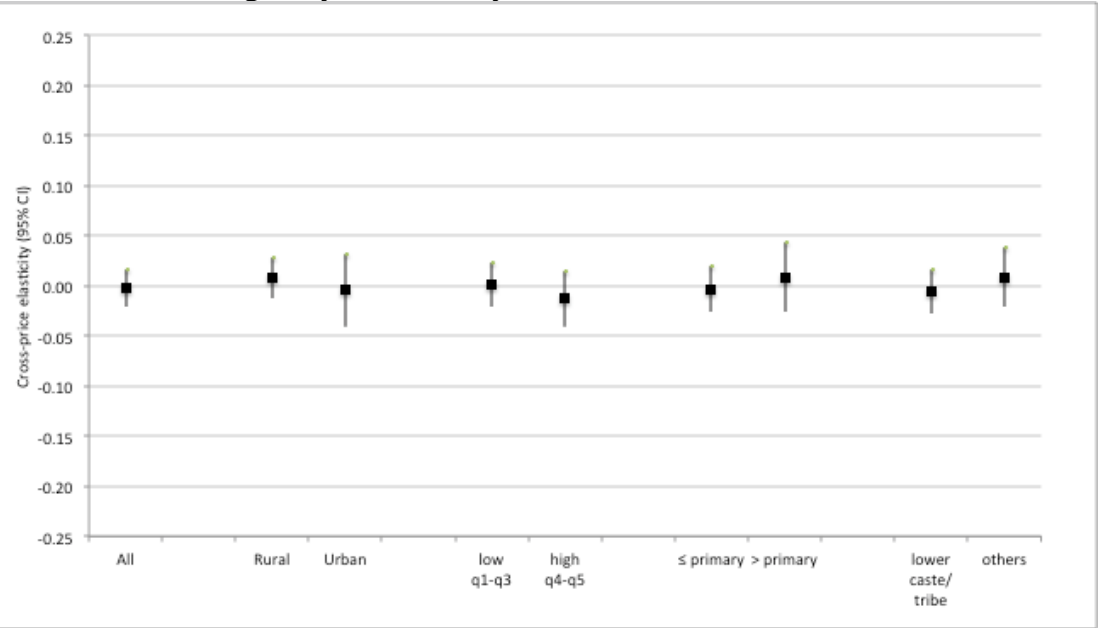


Figure 3. Cross-price elasticities between the demand for cigarettes and the prices of bidis

-Unit values averaged by cluster over all households

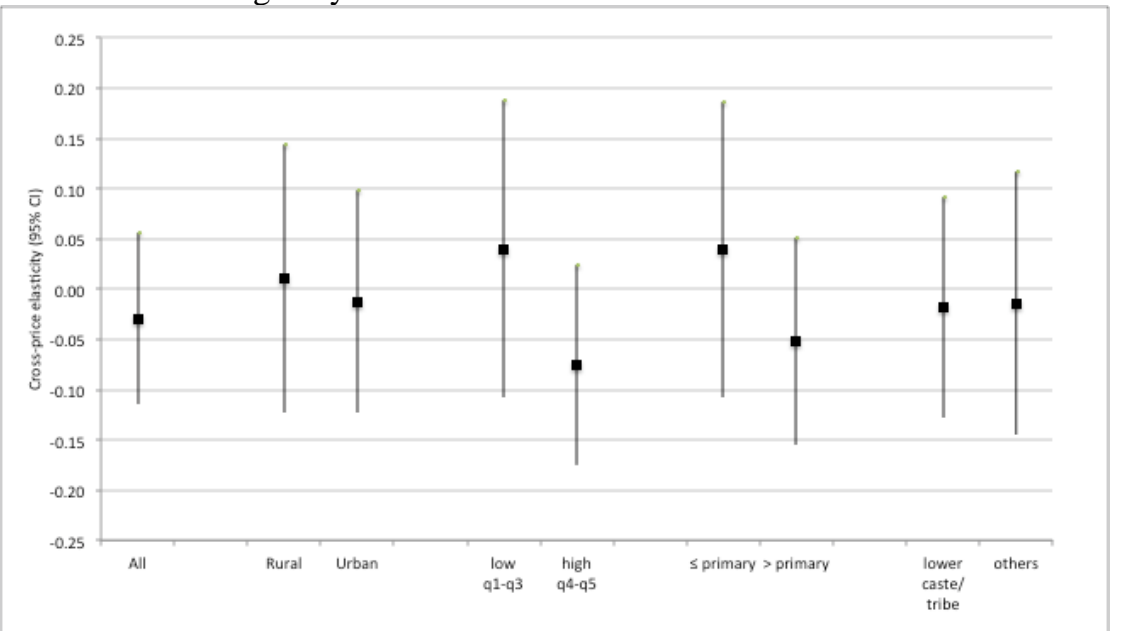

- Unit values averaged by cluster only over households under examination

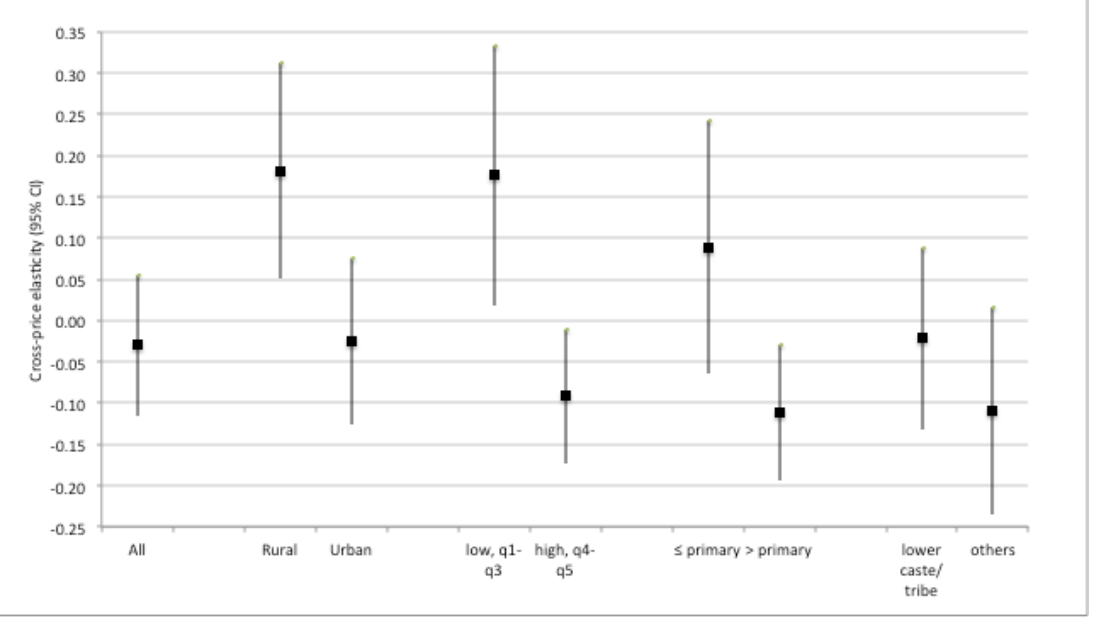

Figure 4. Cross-price elasticities between the demand for cigarettes and the prices of country liquor

-Unit values averaged by cluster over all households

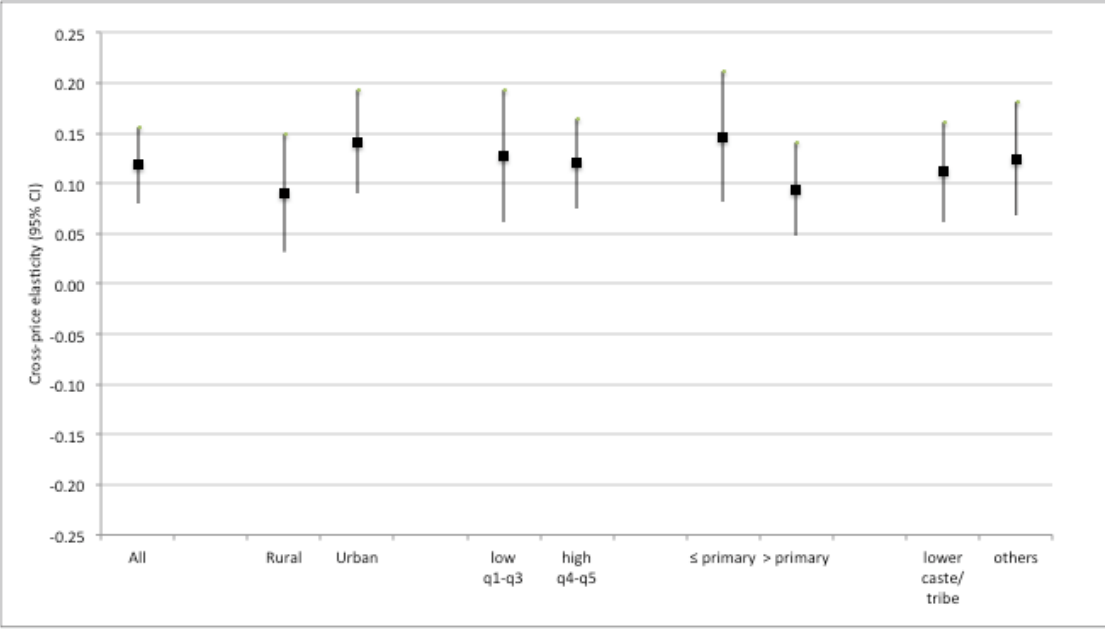

- Unit values averaged by cluster only over households under examination

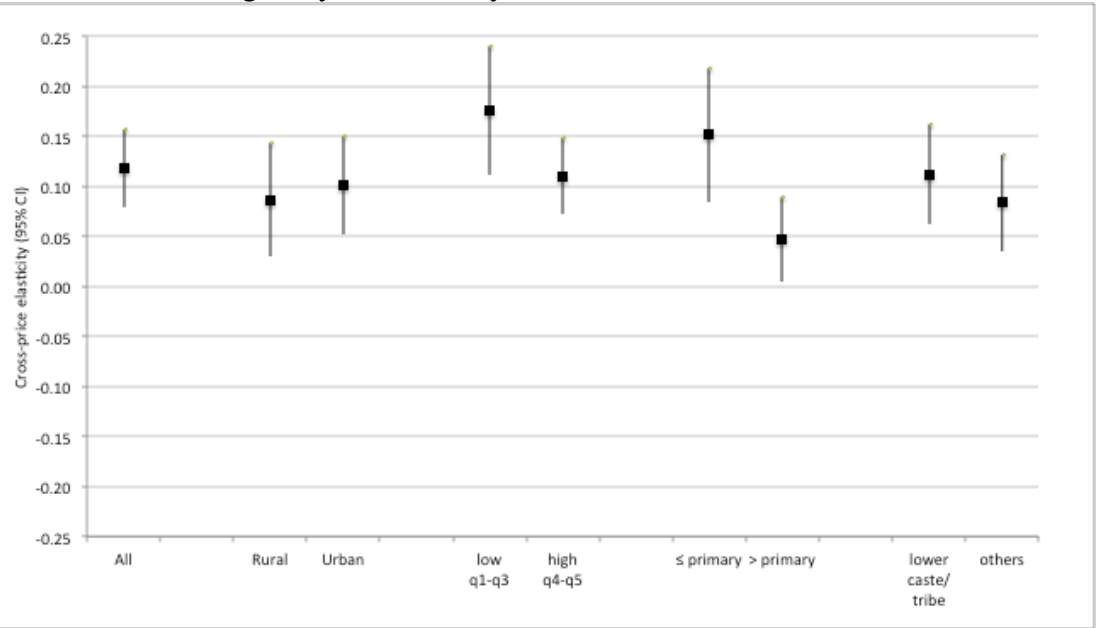


Table A1. National Sample Surveys, 1993/94 - 2007/08

\begin{tabular}{|c|c|c|c|c|c|c|}
\hline \multirow[b]{2}{*}{ Survey round } & \multirow[b]{2}{*}{ Period } & \multicolumn{5}{|c|}{ Sample } \\
\hline & & Rural hh & Urban hh & Total hh & \# of villages & \# urban blocks \\
\hline NSS 50 & Jul 1993 - Jun 1994 & 69,206 & 46,148 & 115,354 & 6,951 & 4,650 \\
\hline NSS 55 & Jul 1999 - Jun 2000 & 71,385 & 48,924 & 120,309 & 5,997 & 4,107 \\
\hline NSS 56 & Jul 2000 - Jun 2001 & 21,649 & 35,624 & 57,273 & 5,433 & 8,918 \\
\hline NSS 57 & Jul 2001 - Jun 2002 & 25,505 & 37,123 & 62,628 & 6,381 & 9,297 \\
\hline NSS 59 & Jan 2003 - Dec 2003 & 26,143 & 14,870 & 41,013 & 6,553 & 3,757 \\
\hline NSS 60 & Jan 2004 - Jun 2004 & 18,975 & 10,656 & 29,631 & 4,755 & 2,669 \\
\hline NSS 61 & Jul 2004 - Jun 2005 & 79,298 & 45,346 & 124,644 & 7,999 & 4,602 \\
\hline NSS 62 & Jul 2005 - Jun 2006 & 18,992 & 20,444 & 39,436 & 4,750 & 5,120 \\
\hline NSS 63 & Jul 2006 - Jun 2007 & 33,146 & 30,583 & 63,729 & 5,573 & 7,698 \\
\hline NSS 64 & Jul 2007 - Jun 2008 & 31,673 & 18,624 & 50,297 & 7,953 & 4,682 \\
\hline
\end{tabular}

Note: hh = households; Figures shown as reported by NSSO; do not necessarily identically match data contained in NSS data files. Source: Government of India, National Sample Survey Organization (NSSO), Ministry of Statistics and Programme Implementation. Various reports. URL: http://www.mospi.gov.in/mospi_nsso_rept_pubn.htm 
